\title{
INFLUÊNCIAS DAS DECISÕES JUDICIAIS NA OFERTA DA EDUCAÇÃO PARANAENSE
}

Simone de Fátima Flach

Resumo: O texto apresenta dados parciais de pesquisa realizada em nível de doutorado sobre o Ensino Fundamental de 9 anos, tendo como objetivo relatar as principais discussões ocorridas no campo judicial e suas influências na oferta da educação no contexto paranaense. Para tanto, faz-se análise de peças processuais, termos de ajustamento de conduta impostos ao poder executivo de alguns municípios e documentos de órgãos normativos dos sistemas de ensino, estadual e municipal. As decisões judiciais, além de causar desgastes sociais e políticos, influenciaram o planejamento político educacional sobre a oferta tanto do ensino fundamental quanto da educação infantil.

Palavras-chave: Ensino fundamental de 9 anos. Educação obrigatória. Direito à educação. Política educacional.

Abstract: The paper presents preliminary data from research (doctoral level) about the new Brazilian elementary school, aiming to report the main discussions that took place in the judicial field and its influence in the provision of education in the context of Paraná. Therefore, we analyze judicial documents, terms of adjustment of conduct imposed on municipal government and education council documents (state and municipal level). The paper shows that judicial decisions caused social and political exhaustion and influenced the educational policy planning on the supply of elementary school and early childhood education.

Keywords: Brazilian elementary school. Obligatory education. Right to education. Educational policy. 


\section{Introdução}

Muitas controvérsias ocorreram face à interpretação da Lei 11.274/06, que alterou o artigo 32 da Lei 9394/96, visto que a ampliação da escolaridade obrigatória exigiu a reorganização da oferta educacional até então existente. Da mesma forma, a Emenda Constitucional 53/06, ao prever o atendimento de 0 a 5 anos na educação infantil criou a interpretação de que o ingresso no ensino fundamental deveria ocorrer ao se completar 5 anos de idade. Essas controvérsias foram geradas pela interpretação legal comprometida com os interesses político-governamentais, sociais e de classe em todo o território nacional. No estado do Paraná, as discussões extrapolaram o campo político-educacional e adentraram o judicial, quando o poder judiciário foi chamado para dirimir conflitos de interesses face à interpretação da legislação recém-criada.

$\mathrm{Na}$ tentativa de explicitar as discussões e decisões judiciais ocorridas no contexto paranaense e suas influências na oferta da educação, este texto enfoca o processo de implantação do Ensino Fundamental de 9 anos em relação à questão da idade de ingresso naquela etapa da educação básica.

Assim, o texto apresentado procura relatar as discussões, decisões judiciais e seus efeitos na oferta da educação paranaense. $\mathrm{O}$ eixo central de discussão está na importância da garantia do direito à educação, a qual contribui para o acesso aos meios que fortalecem a cidadania do indivíduo.

O texto, portanto, configura-se em exercício de exposição parcial de investigação realizada e, como expressão da realidade, é contraditório, singular e particular, e ao mesmo tempo, é geral e universal. Como não pretende ser conclusivo, mas provocativo, oferece suporte às novas e radicais pesquisas sobre a temática em questão. 


\section{Direito à Educação: os interesses em disputa}

A implantação do Ensino Fundamental de 9 anos no contexto brasileiro não ocorre sem disputas teóricas, ideológicas e políticas. A realidade brasileira tem demonstrado, nos últimos anos, quão difícil pode ser a implementação de ações educacionais que objetivem criar mais oportunidades de acesso, permanência e aprendizagem na escola. A ampliação do ensino fundamental de 8 para 9 anos tem ocorrido em um contexto controverso, que vai além das decisões político-governamentais ou mesmo pedagógicas. As implicações impostas pela nova organização educacional vem superando as discussões até então circunscritas ao campo pedagógico e político, ganhando centralidade em outras esferas sociais. Uma dessas esferas é o campo judicial.

A antecipação do ingresso de crianças no ensino fundamental no Sistema Estadual de Ensino paranaense foi uma prática validada pelo Conselho Estadual de Educação, desde meados da década de 90, quando possibilitou que crianças com 6 anos de idade fossem matriculadas no ensino fundamental de 8 anos de duração. Essa autorização, considerada exceção, tornou-se questão significativa anos mais tarde quando se fez argumento de reivindicação para a inclusão de crianças de 5 anos de idade no ensino fundamental de 9 anos. Inserido no debate e controvérsias impostas pelo processo de implantação do Ensino Fundamental de 9 anos, o estado do Paraná viveu grande embate social, político e jurídico.

A implantação do Ensino Fundamental de 9 anos no estado do Paraná foi além da organização político-educacional, adentrando no campo judicial. Os interesses em disputa na oferta e na procura evidenciaram conflitos políticos, pedagógicos e de classe existentes na sociedade paranaense, além daqueles relativos à interpretação normativa referente à matéria. 
Os conflitos políticos ocorreram no campo do planejamento educacional, quando mantenedoras públicas e privadas demonstraram posicionamentos divergentes em relação à organização pedagógica tanto do ensino fundamental quanto da educação infantil. Os conflitos pedagógicos se evidenciaram na carência de debates aprofundados sobre a organização e concepções educacionais para o atendimento das crianças de 6 anos no ensino fundamental e de 5 anos na educação infantil, ficando as duas etapas da educação básica sem um norte sobre os encaminhamentos necessários para o atendimento das crianças na fase de transição. Os conflitos de classe se mostraram presentes na interpretação classista ocorrida pelas mantenedoras privadas, visando a manutenção da situação desigual existente no atendimento da escolaridade obrigatória, quando defenderam o ingresso antecipado na etapa obrigatória.

Os conflitos de interpretação normativa foram iniciados pelas escolas privadas e refletiram no campo pedagógico e político quando levaram a discussão educacional para o campo judicial. Assim, as demandas judiciais e suas respectivas interpretações foram decisivas para o encaminhamento normativo no Sistema Estadual de Ensino e, consequentemente, para a oferta do Ensino Fundamental. Nesse sentido, as discussões e decisões impostas pela seara judicial se tornaram centrais no processo de implementação do Ensino Fundamental de 9 anos no contexto educacional paranaense.

As insatisfações no processo de implantação do Ensino Fundamental de 9 anos se tornaram significativas quando o Conselho Estadual de Educação - CEE-PR aprovou a Deliberação 03/06, estabelecendo a obrigatoriedade da nova medida e a data de corte para o ingresso:

Art. 12 - Para matrícula de ingresso no $1 .^{\circ}$ ano do ensino fundamental de 9 anos de duração o educando deverá ter seis anos completos ou a completar até $1^{\circ}$ de 
março do ano letivo em curso.

$\S 1 .^{\circ}$ - O aluno que estiver cursando a educação infantil e completar seis anos de idade no decorrer do ano letivo não poderá ingressar no ensino fundamental nesse mesmo ano. (Paraná, 2006 a)

Conforme já exposto, havia a prática, em especial das escolas privadas, de matricular no Ensino Fundamental de 8 anos crianças com 6 anos de idade. O corte etário estabelecido pelo CEE-PR para o ingresso no Ensino Fundamental de 9 anos foi entendido como impossibilidade de continuar na prática já existente, visto que, segundo o entendimento corrente, a ampliação era de incorporação da última etapa da educação infantil no Ensino Fundamental. Isso causou insatisfação de pais, que entendiam que seus filhos repetiriam uma etapa já cumprida, pois as crianças com idade inferior a 6 permaneceriam na educação infantil e aquelas com 6 anos seriam matriculadas no $1^{\circ}$ ano da nova organização. Segundo essa lógica, as escolas privadas passaram a defender o ingresso aos 5 anos de idade, conforme o interesse dos pais.

No campo específico do ensino público, a manifestação foi a respeito da insuficiência de recursos para o cumprimento da norma, visto que as Prefeituras não estavam preparadas para implantar a medida.

Atendendo ao clamor dos setores privado e público houve a flexibilização para a implantação da nova organização, com a possibilidade de permanecer a organização anterior, sem que houvesse alteração na data de corte, através da Deliberação 05/06. Houve, então, a autorização (em caráter excepcional e exclusivamente para o ano letivo de 2007) para a matrícula de alunos no ensino fundamental de 8 anos, conforme estabelecia a regra anterior: para aqueles que completassem 6 anos de idade até o dia $1^{\circ}$ de março. A essa norma houve reação coletiva de Escolas Privadas da Capital e do interior do Estado, totalizando 
14 instituições que impetraram Mandado de Segurança contra o CEE-PR, visando matricular no Ensino Fundamental de 9 anos as crianças que completassem a idade legal para matrícula após a data de $1^{\circ}$ de março; ou seja, a intenção era matricular as crianças que completassem 6 anos até o dia 31 de dezembro.

Alguns argumentos evidenciados na Petição Inicial do Conjunto de Escolas Privadas evidenciam o entendimento sobre o processo educacional existente na educação infantil e sobre a nova organização de Ensino Fundamental proposta pelo legislador. Dentre esses argumentos alguns podem ser considerados como verdadeiras "pérolas educacionais", por considerarem a necessidade de continuidade do processo educacional no ensino fundamental de crianças com idade inferior à permitida entendendo que as mesmas já estariam "alfabetizadas na última série da Educação Infantil", conforme autos do Processo 2972/2006. (Paraná, 2006b, p. 11). Esse argumento mostra a organização da educação infantil utilizada por tais instituições, a qual passa ao largo dos objetivos dessa etapa.

No entendimento das Instituições privadas além da perspectiva seriada da Educação Infantil, as crianças que estavam na última etapa da educação infantil e iniciassem o $1^{\circ}$ ano do Ensino Fundamental de 9 anos ficariam obstadas de avanço pedagógico visto que "na prática não teriam qualquer evolução, pois o conteúdo do primeiro ano seria praticamente idêntico ao último ano da educação infantil" (Paraná, 2006 b, p. 11).

Esse entendimento corrobora a prática existente e o entendimento de que o $1^{\circ}$ ano do Ensino Fundamental de 9 anos nada mais seria do que a junção do último ano da educação infantil a esta nova organização, sem considerar as finalidades diferenciadas das duas etapas.

A pretensão das Escolas privadas foi deferida pela $1^{\text {a }}$ Vara da Fazenda Pública, Falência e Concordatas de Curitiba, 
autorizando a matrícula de crianças com 6 anos de idade no Ensino Fundamental de 8 anos de duração e, de 5 anos de idade, no Ensino Fundamental com duração de 9 anos. Essa decisão foi revogada pelo Tribunal de Justiça em 05/03/2007. No entanto, devido ao princípio da não-retroatividade das matrículas já efetivadas foram mantidas.

O Ministério Público, enquanto fiscal da aplicabilidade das normas legais de forma equitativa a todos os cidadãos, através da Promotoria de Proteção à Educação, propôs Ação Civil Pública pleiteando a suspensão do art. 12 da Deliberação 03/06, o qual estabelecia o corte etário em 6 anos completos até o dia $1^{\circ}$ do mês de março. A Ação Civil Pública foi distribuída por dependência à mesma Vara onde já estavam em trâmite os Autos de Mandado de Segurança nº 2972/2006, proposto pelas Escolas Privadas.

Segundo o Ministério Público, havia motivos para questionar a validade e eficácia do ato normativo (Deliberação 03/06), visto que as crianças nascidas entre 02 de março e 31 de dezembro, a cada ano letivo, estariam impedidas de ingressar no Ensino Fundamental de 9 anos.

Alguns argumentos retirados da peça processual são sintetizados a seguir:

- Haveria em torno de 84 mil crianças/ano obstadas de ingresso na escola;

- Com a aprovação da Emenda Constitucional 53/06, a educação infantil passou a ser a etapa específica para o atendimento de crianças com idade entre 0 e 5 anos;

- Após os 5 anos de idade as crianças deveriam ser matriculadas no ensino fundamental;

- Com a substituição do FUNDEF pelo FUNDEB (art. $2^{\circ}$ da EC 53/06) os Gestores Públicos não poderiam alegar falta de recursos para a inclusão das crianças de 5 anos, visto que "um maior número de matrículas [...] é fator de 
aumento de receitas públicas por ocasião da distribuição e transferência constitucional das verbas do Fundeb aos Estados e Municípios."

- Retrocesso escolar das crianças matriculadas na rede privada, os quais já estariam alfabetizados na última etapa da educação infantil.

Face aos argumentos, o Ministério Público requeria:

- Suspensão da vigência do art. 12 da Deliberação 09/01 do CEE-PR;

- Definição, pelo CEE-PR, de regra de transição para o ano letivo de 2008, visando não causar prejuízo às crianças nascidas entre 02 de março e 31 de dezembro de 2001, possibilitando promoção diretamente ao $2^{\circ}$ ano do Ensino Fundamental de 9 anos para aquelas que estivessem matriculadas na educação infantil em 2007;

- Comunicação à Secretaria de Estado da Educação, Conselho Estadual de Educação e UNDIME-PR para as providências necessárias, sob pena de multa diária de $\mathrm{R} \$$ 1.000,00 para aqueles que não a cumprissem (CEE-PR, SEED-PR e Municípios integrantes do Sistema Estadual de Ensino).

Houve deferimento da medida liminar nos seguintes termos: suspensão do art. 12 da Deliberação 03/06; prazo de 30 dias para o CEE-PR editar regra de transição para o ano letivo de 2008 nos termos solicitados pelo Ministério Público, sob pena de crime de desobediência; e cumprimento da decisão pelos órgãos estaduais e municipais (dos 391 municípios) pertencentes ao Sistema Estadual de Ensino.

Algumas considerações se fazem necessárias em razão dos argumentos e do pedido na Ação Civil Pública no 402/07, os quais foram acatados integralmente na Decisão Judicial: 
- As crianças que estariam obstadas de ingressar na escola (aproximadamente 84 mil crianças) seriam aquelas que estariam situadas no espaço legal após a educação infantil e antes de terem 6 anos para o ensino fundamental. Portanto, tais crianças deveriam estar matriculadas na educação infantil, por ainda estarem no espaço de alcance dos 5 anos previstos para o atendimento nessa etapa. A esse respeito é prática na sociedade brasileira, além de pressuposto matemático, que ninguém tem determinada idade antes de completá-la. Se assim fosse, no ano em que se completa 18 anos, mas antes de efetivamente o ter completado, os brasileiros estariam aptos para ingressarem no serviço militar, para responder processo penal e assim por diante.

- Mesmo após a concessão da Liminar solicitada, as aproximadamente 84 mil crianças não "foram matriculadas". Ou seja, o número utilizado para os argumentos não foram validados pelas matrículas efetivadas no período imediatamente posterior. Conforme dados publicados pelo INEP, o número de alunos atendidos nos anos iniciais do ensino fundamental no Paraná foram os seguintes: 838.928 em 2006; 866.588 em 2007 e 870.574 em 2008. Mesmo com a autorização e determinação judicial para a efetivação das matrículas de crianças com 5 anos de idade, os números levantados pelo Ministério Público não se mostraram reais. Portanto, tais alunos deveriam ser atendidos na educação infantil, com espaço, materiais e procedimentos pedagógicos adequados as suas necessidades.

- $\quad$ aumento de receitas públicas por ocasião da distribuição e transferência constitucional das verbas do Fundeb não é imediato conforme sugerido pelo Ministério Público, pois, conforme estabelecido na Lei 11.494/2007, o 
repasse dos recursos efetivar-se-á conforme dados do Censo Escolar mais atualizado. No ano de 2007, o Censo Escolar mais atualizado seria aquele realizado em 2006. Portanto, os municípios estariam mais uma vez se responsabilizando pelo atendimento de um número maior de alunos, sem a contrapartida financeira, tão necessária para aqueles que necessitavam de tais recursos.

- Quanto ao retrocesso escolar das crianças matriculadas na rede privada há questões de cunho organizacional e pedagógico. Não há como se considerar retrocesso escolar, se não houve avanço para a etapa seguinte. Quanto ao processo de alfabetização já concluído, é possível identificar um entendimento de alfabetização enquanto decodificação de símbolos gráficos, ou ainda como processo inicial de escolarização. Essa concepção já foi ultrapassada no campo educacional, visto que a alfabetização atualmente é entendida como processo que se consolida em vários anos e pela prática da leitura e da escrita. Portanto, às crianças "já alfabetizadas" na educação infantil seria justa e necessária a reorganização pedagógica daquela etapa para que o processo fosse continuado e não repetido, como sugere o Ministério Público.

- Da mesma forma a sugestão, acatada pelo Magistrado, de matricular alunos diretamente no $2^{\circ}$ ano do ensino fundamental de 9 anos lesa o direito as crianças completarem o ensino fundamental, sem pular etapas, visto que um dos objetivos da ampliação é a melhoria do desempenho dos alunos nessa etapa da educação básica.

Assim, a política educativa de ampliação da escolaridade obrigatória com vistas à melhoria da educação brasileira, proporcionando mais tempo para os alunos aprenderem mais e 
melhor foi totalmente ignorada, face aos argumentos fechados, que não vislumbraram a totalidade da questão.

A concessão de Medida Liminar foi, no mínimo, uma afronta ao direito das crianças paranaenses de estar na escola por um período de tempo maior e aprender mais. A aquisição de conhecimentos por determinada classe torna-se fundamental ao exercício de seus direitos e, consequentemente, no exercício pleno da cidadania. Nesse sentido, o direito de ingresso no ensino fundamental é acompanhado paralelamente pelo "nãodireito" à educação infantil, e isso faz toda a diferença para os filhos da classe trabalhadora.

A esse respeito, tornam-se extremamente importantes as reflexões feitas por Antonio Gramsci, a respeito da formação de intelectuais:

Decerto, a criança de uma família tradicional de intelectuais supera mais facilmente o processo de adaptação psicofísico; quando entra na sala de aula pela primeira vez, já tem vários pontos de vantagem sobre seus colegas, possui uma orientação já adquirida por hábitos familiares: concentra a atenção com mais facilidade, pois tem o hábito da contenção física, etc. [...] Também o regime alimentar tem importância, etc., etc. Eis por que muitas pessoas do povo pensam que, nas dificuldades do estudo, exista um 'truque' contra elas (quando não pensam que são estúpidos por natureza): [...]. Numa nova situação, estas questões podem tornar-se muito ásperas e será preciso resistir à tendência a facilitar o que não pode sê-lo sob pena de ser desnaturado. (Gramsci, 2006, p. 52)

Como os conflitos gerados pela implantação do Ensino Fundamental de 9 anos envolvem interesses coletivos em sentido amplo e os direitos à educação dos filhos da classe 
trabalhadora em específico, é preciso olhar a questão sob a ótica de possibilidade de ampliação de conhecimentos e consequentemente de cidadania. As crianças oriundas da classe que vive do trabalho precisam que suas necessidades e direitos sejam considerados na implementação de políticas públicas e assim não se adaptarem aos interesses da minoria privilegiada. "Se se quiser criar uma nova camada de intelectuais, chegando às mais altas especializações, a partir de um grupo social que tradicionalmente não desenvolveu as aptidões adequadas, será preciso superar enormes dificuldades" (Gramsci, 2006, p. 52). Entendemos que as dificuldades a que se refere Gramsci são aquelas que possibilitam a diferenciação entre os indivíduos na sociedade capitalista: a influência do poder econômico, suas condições sociais e culturais e as possibilidades educacionais existentes. O Ensino Fundamental de 9 anos, na atual sociedade regida pelo capital, pode representar ampliação da oportunidade de acesso pela classe trabalhadora ao saber sistematizado. No entanto, as condições para que os sujeitos possam usufruir desse acesso nem sempre estão disponíveis.

\section{Repercussões Locais}

Face ao deferimento da Medida Liminar que atingia todos os municípios vinculados ao Sistema Estadual de Ensino, inúmeras ações foram deflagradas pelos representantes do Ministério Público em todo o território paranaense, visando o seu cumprimento. Tais ações se efetivaram através de comunicados oficiais aos gestores públicos municipais indicando a necessidade do estrito cumprimento da decisão judicial, através da efetivação de matrículas para todas as crianças que completassem 6 anos até o final do ano de 2007, induzindo à ampliação das oportunidades de acesso, sem que as condições institucionais para a sua garantia estivessem asseguradas. 
Importante esclarecer que a decisão liminar proferida nos autos da mencionada ação, com alcance regional e de compulsória observância para todas as Secretarias Municipais de Educação suspendeu a aplicação do artigo 12 da Deliberação n. 03/2006 do Conselho Estadual de Educação, bem como determinou o cumprimento da decisão pelos órgãos estaduais e municipais dos 391 municípios ligados à Educação, sob pena de crime de prevaricação, razão pela qual Vossa Senhoria, dentro de sua atribuição e responsabilidade, por conta disso, está rigorosamente obrigada a fornecer os meios, instrumentalizar, comprovar e garantir a matrícula de todas as crianças com seis anos de idade completos ou a completar até 31 de dezembro de 2007 até a data-limite de 02 de abril de 2007, sob pena de responsabilidade criminal e administrativa inclusive perante esta Promotoria de Justiça e Defesa da Educação. (Ministério Público Estadual do Paraná, 2007a)

O cumprimento da medida judicial possibilitou o ingresso no ensino fundamental de crianças que estariam, provavelmente, excluídas do processo educativo sistematizado. No entanto, no arrepio do cumprimento judicial, a inclusão das crianças com menos de 6 anos no ensino fundamental, segundo o entendimento do Ministério Público Estadual, deveria ocorrer sob quaisquer condições, conforme evidenciado no mesmo documento.

$\mathrm{Na}$ eventual existência de dificuldades e carências materiais de relevo, como falta de tempo hábil para contratação de professores ou mesmo necessidade de construção de mais salas de aula, a sugestão inicial é que seja realizado o agrupamento das turmas do pré-3 (pré escola ou jardim 3) com as turmas do primeiro ano do ensino fundamental com nove anos 
de duração, mormente considerando a identidade de conteúdos hoje praticada, situação que exigirá que a respectiva Secretaria Municipal de Educação repasse a esta Promotoria de Justiça todas as informações e dados disponíveis para exame conjunto e posterior lavratura de termo de ajustamento de conduta, se for o caso. (Ministério Público Estadual do Paraná, 2007a)

A evidência de que as condições de atendimento não estavam na pauta de discussões do Ministério Público é corroborada no trecho a seguir:

Certeza, apenas uma: qualquer que seja o planejamento ou mesmo situação de dificuldade enfrentada não afastará a imperiosa necessidade de que a decisão liminar e o direito fundamental de educação e acesso ao ensino fundamental de todas as crianças nascidas entre 01 de janeiro a 31 de dezembro de 2001 na rede pública e privada seja imediata e urgentemente assegurada com prioridade absoluta, sob pena de responsabilidade da respectiva Secretaria Municipal de Educação. (Ministério Público Estadual do Paraná, 2007a)

Não é novidade na história da educação brasileira o descaso do poder público pela educação da população, mas a ignorância sobre as condições reais de atendimento pode levar a um pseudoentendimento sobre a qualidade do ensino oferecido e sobre o cumprimento do direito à educação. $\mathrm{O}$ direito à educação se assegura com condições adequadas: número de alunos adequado para o trabalho educativo a ser desenvolvido por professor, estrutura didático-pedagógica para a efetivação do processo ensino aprendizagem, professores em número suficiente para atender à demanda; estrutura física compatível com o número de alunos, dentre outras e não apenas com o acesso à escola. 
O entendimento da questão evidenciado não foi educacional, mas apenas no estrito cumprimento da decisão judicial, a qual não era definitiva, pois carecia de julgamento do mérito. Esse entendimento induziu a uma precariedade ainda maior da escola pública paranaense. Essa decisão, puramente administrativa, sem vínculo com a realidade concreta, não colabora para o direito à educação (de qualidade) ser efetivamente usufruído pela população escolar.

$\mathrm{Na}$ defesa do direito à educação, a quantidade pressupõe a qualidade. Para a quantidade ser atingida é necessário a existência da qualidade, visto que ambas constituem a mesma realidade; caso contrário, o que ocorre é apenas falácia sobre $\mathrm{o}$ atendimento quantitativo, sem o devido compromisso com o real direito à educação capaz de possibilitar aos indivíduos a superação das desigualdades sociais até então existentes.

Além da exigência legal para a implantação do Ensino Fundamental de 9 anos, o cumprimento da decisão judicial colaborou para que um número maior de municípios paranaenses implantassem o Ensino Fundamental de 9 anos, conforme demonstrado na tabela a seguir.

Tabela 01- Diagnóstico da implantação do ensino fundamental de 9 anos no Estado do Paraná- 2005-2009

\begin{tabular}{|c|c|c|c|c|}
\hline $\begin{array}{c}\text { Total de } \\
\text { Municípios no } \\
\text { Estado }\end{array}$ & Ano & $\begin{array}{c}\text { Ens. Fund.9 anos } \\
\text { não implantado }\end{array}$ & $\begin{array}{c}\text { Ens. Fund.9 anos } \\
\text { implantado }\end{array}$ & $\begin{array}{c}\text { Porcentagem de } \\
\text { Implantação }\end{array}$ \\
\hline \multirow{3}{*}{399} & 2005 & 395 & 4 & $1 \%$ \\
\cline { 2 - 5 } & 2006 & 396 & 3 & $0,75 \%$ \\
\cline { 2 - 5 } & 2007 & 156 & 243 & $60,90 \%$ \\
\cline { 2 - 5 } & 2008 & 43 & 356 & $89,22 \%$ \\
\cline { 2 - 5 } & 2009 & 25 & 374 & $94 \%$ \\
\hline
\end{tabular}

Fonte: MEC/INEP/Censo Escolar/Sinopses Estatísticas do Período.

No entanto, o aumento evidente de municípios que implantaram a nova organização, gerou uma distorção na política educacional cujo objetivo deveria dar mais tempo e 
possibilidades aos filhos da classe trabalhadora de ampliarem seu universo de conhecimento. Assim, a decisão tomada a distância da realidade socioeducacional fragmentou algo que pela sua natureza não poderia ser fragmentado sob pena de perder a especificidade de possibilitar a transformação da realidade educacional existente. Ao "obrigar" os gestores públicos a matricular as crianças mais novas "qualquer que seja o planejamento ou mesmo a situação de dificuldade enfrentada", o "fiscal da lei" ignorou as reais condições existentes para o cumprimento da medida, induzindo ao atendimento precário ou mesmo forçando a substituição da pré-escola pelo ano inicial do ensino fundamental.

Tabela 02- Evolução do atendimento na Pré-Escola no Estado do Paraná- 2006-2007

\begin{tabular}{|c|c|c|c|c|c|c|}
\hline Ano & $\begin{array}{c}\mathbf{N}^{\mathbf{0}} \text { de } \\
\text { turmas }\end{array}$ & Variação & $\%$ & $\begin{array}{c}\text { Número } \\
\text { de Alunos }\end{array}$ & Variação & $\%$ \\
\hline 2006 & 13.020 & - & - & 252.840 & - & - \\
\hline 2007 & 9.953 & -3.070 & $-24 \%$ & 179.528 & -73.312 & $-29 \%$ \\
\hline
\end{tabular}

Fonte: MEC/INEP/Censo Escolar/Sinopses Estatísticas do Período.

Os dados da Tabela 2 podem ser apontados como indicativos do impacto das decisões judiciais no atendimento da pré-escola no Estado do Paraná. Evidencia-se a redução de 73.312 alunos atendidos ou de 29\%. Em contrapartida, houve aumento das matrículas no ano inicial do Ensino Fundamental, embora não na mesma proporção da redução apresentada na Pré-escola, conforme dados da Tabela 3.

Tabela 03 - Evolução do atendimento no ano inicial do ensino fundamental de 9 anos no Estado do Paraná - 2006 - 2007

\begin{tabular}{|c|c|c|c|c|}
\hline Ano & $\mathbf{N}^{0}$ de turmas & Variação & $\begin{array}{c}\text { Número de } \\
\text { Alunos }\end{array}$ & Variação \\
\hline 2006 & 672 & & 17.565 & \\
\hline 2007 & 3.760 & +3.112 & 75.599 & +58.034 \\
\hline
\end{tabular}

Fonte: MEC/INEP/Censo Escolar/Sinopses Estatísticas do Período 
Os dados oficiais disponíveis demonstram a redução de 73.312 alunos atendidos na pré-escola e um aumento de 58.034 no ano inicial do ensino fundamental de 9 anos. A diferença de 15.278 alunos não atendidos em 2007 nos leva a considerar que o impacto das discussões a respeito do ingresso no ensino fundamental foi extremamente negativo em relação ao acesso à escola e consequentemente do direito à educação das crianças na faixa etária entre 5 e 6 anos de idade. Essa diferença nos leva a afirmar que houve uma substituição da pré-escola pelo ano inicial do ensino fundamental, além de reduzir o atendimento da faixa etária em sua totalidade.

Ao considerarmos o número de alunos no Ensino Fundamental, na faixa etária de 0 a 10 anos, nos anos de 2006 e 2007, verificamos que o aumento no atendimento foi de 18.374 alunos, evidenciando que, mesmo por força das decisões judiciais, não houve o ingresso de aproximadamente 84 mil crianças como argumentado pelo Ministério Público ao solicitar Medida Liminar obrigando os gestores públicos a matricular antecipadamente as crianças no ensino fundamental.

Tabela 04- Número de alunos atendidos no ensino fundamental no Estado do Paraná na faixa etária de 0 a 10 anos - 2006 - 2007

\begin{tabular}{|c|c|c|}
\hline Ano & $\begin{array}{c}\text { Alunos com idade entre 0 } \\
\text { e 10 anos }\end{array}$ & Diferença no período \\
\hline 2006 & 752.399 & \multirow{2}{*}{+18.374} \\
\hline 2007 & 770.773 & +10 \\
\hline
\end{tabular}

Fonte: MEC/INEP/Censo Escolar/Sinopses Estatísticas do Período

Os recursos impetrados pelo Sistema Estadual de Ensino do Paraná contra as Liminares relativas às Instituições Privadas e à Ação Civil Pública relativa ao atendimento no Ensino Público foram suspensos, conforme exposto a seguir:

\footnotetext{
Desse modo, DEFIRO parcialmente o pedido, tão somente para suspender a decisão na parte em
} 
que obrigou a Rede Estadual de Ensino Público à imediata inclusão de todas as crianças com 6 anos completos ou a completar no decorrer do ano letivo de 2007, na $1^{\text {a }}$ série do ensino fundamental de 9 anos de duração e seus consectários, proferida na Ação Civil Pública $n^{\circ} 402 / 2007$, que tramita na $1^{\text {a }}$ Vara da Fazenda Pública do Foro Central da Região Metropolitana de Curitiba.

Não obstante a decisão de fls. 107/113 tenha se referido à suspensão na parte em que obrigou a Rede Estadual de Ensino Público, como a solução de primeiro grau determinou o cumprimento da ordem pelos órgãos Estaduais e Municipais, por certo que a suspensão da obrigação imediata inclusão de todas as crianças com 6 anos completos ou a completar no decorrer do ano letivo de 2007, na $1^{\text {a }}$ série do ensino fundamental de 9 anos de duração, estende-se às escolas do Sistema Estadual de Ensino, inclusive às escolas da rede municipal de ensino de Curitiba, conforme se pode observar da própria fundamentação do decisum. (Paraná, 2007b)

Note-se que em maio de 2007 já havia decorrido pelo menos um terço do ano letivo. Portanto, as matrículas para o ano em curso já haviam sido efetivadas, principalmente em razão da pressão exercida pelo Ministério Público nos diversos municípios sob sua alçada de competência. Inclusive os 8 municípios que estavam fora das decisões judiciais, por já terem constituído seus próprios Sistemas de Ensino, sofreram com os reflexos das discussões.

O município de Toledo, que havia constituído seu Sistema de Ensino e o Conselho Municipal de Educação exercia função normativa, estando fora dos efeitos das liminares concedidas contra o Sistema Estadual de Ensino, firmou Termo de Compromisso de Ajustamento de Conduta, em 
26 de março de 2007, junto à $4^{\text {a }}$ Promotoria de Justiça da Comarca de Toledo - Promotoria de Defesa da Criança e do Adolescente e $2^{\text {a }}$ Promotoria de Justiça da Comarca de Toledo - Promotoria de Defesa do Patrimônio Público, reconhecendo a "a impossibilidade de fixação de critério cronológico de acesso ao ensino fundamental no início do ano letivo, por intermédio de corte etário, no âmbito do Sistema Municipal de Ensino" e assumindo a responsabilidade de manter os alunos não-atendidos no Ensino Fundamental na Pré-Escola e assegurando-lhes "o ingresso na $2^{\mathrm{a}}$ série do ensino fundamental de nove anos, no ano letivo de 2008, garantido-se dessa forma tratamento isonômico mediante compatibilização de faixa etária" (Ministério Público do Estado do Paraná, 2007 a).

As discussões travadas no processo de alteração das normas de ingresso no ensino fundamental nos municípios com Sistema Próprio sofreram pressão dos representantes do Ministério Público para que as alterações ocorressem rapidamente.

Em 07 de dezembro de 2007 o Conselho Municipal de Londrina aprovou a Deliberação 03/07 estabelecendo normas para a implantação gradativa do Ensino Fundamental de 9 anos de duração, a partir do ano de 2009.

O município de Araucária também sofreu Ação Civil Pública em relação ao corte etário. O Conselho Municipal de Educação de Araucária, assim se expressou:

O entendimento deste Conselho é de que o atendimento na Educação Infantil deve acontecer até que a criança tenha 6 anos completos, ou seja, se a criança tiver 5 anos, 11 meses e 29 dias, ela ainda tem cinco anos e deve ser atendida na Educação Infantil. Como o ano escolar é estabelecido num calendário letivo, para ingresso na $1^{\text {a }}$ série, a criança deve ter completado seis anos no início do ano letivo e para que ela não fique sem atendimento educacional, é necessário que permaneça 
na educação infantil até que complete seis anos. A Lei Federal $\mathrm{n}^{\mathrm{o}} 11.274 / 06$, ao alterar o artigo 32 da LDB, refere-se a obrigatoriedade do ensino fundamental com duração de nove anos 'iniciando-se aos 6 (seis) anos de idade', não aos cinco anos. A Emenda Constitucional $n^{\circ}$ 53/2006 não altera esse entendimento, pois a idade de cinco anos termina somente quando a criança completa seis anos.

$[\ldots]$

Todavia, se por força de uma liminar judicial, é necessário incluir crianças que possam vir a completar seis anos somente ao final do ano em que cursam a $1^{\text {a }}$ série do Ensino Fundamental (portanto, com cinco anos), torna-se ainda mais urgente a reorganização da Proposta Pedagógica, a formação continuada dos profissionais e trabalhadores da educação, a readequação do espaço escolar e da estrutura física das Unidades Educacionais que ofertam Ensino Fundamental, levando-se em consideração a fundamentação teórica expressa no Parecer CME/Araucária nº 08/2006. (Araucária, 2007).

Dessa forma, para atender a Medida Liminar, o Conselho Municipal de Araucária aprovou a Resolução 01/07 estabelecendo que a criança deverá completar 6 anos no decorrer do ano civil do ingresso no ensino fundamental de 9 anos.

O município de Ponta Grossa apresentou realidade diferenciada, transformando-se em uma "ilha" no emaranhado de Ajustes de Condutas e Ofícios emanados do Ministério Público. O Conselho Municipal de Educação, juntamente com a Secretaria Municipal de Educação de Ponta Grossa, mantiveram um diálogo muito próximo à Promotoria de Proteção à Infância e Juventude, protelando a flexibilização do atendimento de crianças com 5 anos no ensino fundamental para o ano de 2009, quando em dezembro de 2008, por força de Medida Liminar solicitada pela Promotoria de Proteção à Educação, o município 
foi obrigado a matricular crianças daquela faixa etária no ensino fundamental.

\section{Considerações Finais}

As discussões e decisões da seara judicial causaram inúmeros desgastes políticos e sociais, além de comprometer a oferta da educação infantil em todo o território paranaense. A ampliação do ensino fundamental, medida a ser comemorada por toda a população, no Paraná pouco colaborou para que o direito à educação fosse efetivamente assegurado. Isso ocorreu, contraditoriamente, sob a tutela do Poder Judiciário, evidenciando situações que, ao invés de contribuir para o avanço educacional, fortaleceu o status quo vigente no setor.

A política educacional paranaense foi delineada por decisões judiciais. Dessa forma a implantação do Ensino Fundamental de 9 anos induziu a criação (senão manutenção) de estratégias político-educacionais para o cumprimento das exigências judiciais.

Assim, as decisões judiciais contribuíram para:

- redução da educação infantil, quando as crianças foram matriculadas aos 5 anos no ensino fundamental;

- encurtamento do ensino fundamental, quando autorizada (senão exigida) pelo judiciário a matrícula no $2^{\circ}$ ano;

- fortalecimento das instituições privadas ao terem seus interesses mantidos e "adotados" pelos "fiscais da lei";

- desconsideração pelo direito das crianças colocadas no ensino fundamental sem as necessárias adequações estruturais, curriculares e pedagógicas;

- manutenção da lógica organizacional praticada no ensino fundamental de 8 anos;

- retrocesso no processo de gestão democrática do ensino 
público, quando os gestores municipais foram obrigados a providenciar a imediata implantação da medida, sem possibilidades de discussões aprofundadas sobre seus efeitos na qualidade do ensino oferecido à população;

- retrocesso no exercício democrático exercido pelos Conselhos de Educação, Estadual e Municipais, quando foram levados a expedir normas equivocadas justificadas por pareceres contraditórios.

Os conflitos de interesses levantados nas demandas judiciais analisadas foram além dos fundamentos legais expostos pelas partes envolvidas. A realidade demonstrou: a influência dos documentos judiciais na implementação de políticas públicas, a fragilidade dos gestores públicos diante dos conflitos existentes; os interesses das instituições privadas diante da possibilidade de maior lucratividade; as estratégias político-financeiras para o atendimento das medidas liminares.

A ampliação do ensino fundamental no Paraná estabeleceu um marco importante na explicitação do direito à educação e sua vinculação com os interesses da classe que tem o poder econômico e daquela que depende das possibilidades financeiras do poder público para que seus direitos sejam garantidos. Nessa luta de interesses divergentes, "a corda arrebentou do lado mais fraco", ou seja, as crianças paranaenses tiveram o seu direito à educação infantil reduzido, pois foram incluídas antecipadamente no ensino fundamental. Houve, portanto, dupla usurpação do direito à educação dessas crianças, visto que foram impossibilitadas de usufruírem da educação infantil e ingressaram forçosamente no ensino fundamental, sem que esse tivesse adequadamente preparado para recebê-las.

A ampliação foi entendida como antecipação. O entendimento de antecipação manteve o status quo, ou seja, a desnecessidade de reorganizar o ensino fundamental, considerando que 
quantidade e qualidade constituem-se em um todo único. Essa perspectiva evidencia uma concepção conservadora, segundo a qual não há necessidade de alterar a realidade, pois, sua organização já atende os interesses da sociedade. Em uma sociedade capitalista, os interesses não são explícitos para todos. Mascaram-se os verdadeiros objetivos, induz-se à crença de que há compromissos com a população que vive do trabalho, mas implicitamente tais compromissos vinculam-se a outra classe. A implantação do Ensino Fundamental de 9 anos no estado do Paraná evidenciou essa concepção conservadora.

\section{Referências Bibliográficas}

ARAUCÁRIA, CME. Parecer 01/07. Aprovado em 24 de maio de 2007. Alteração da Resolução CME/Araucária $n^{\circ}$ 08/2006 e dá outras providências.

BRASIL. CASA CIVIL, Subchefia para assuntos jurídicos. Lei $\mathbf{n}^{\mathbf{0}}$ 11.274, Altera a redação dos arts. 29, 30, 32 e 87 da Lei no 9.394, de 20 de dezembro de 1996, que estabelece as diretrizes e bases da educação nacional, dispondo sobre a duração de 9 (nove) anos para o ensino fundamental, com matrícula obrigatória a partir dos 6 (seis) anos de idade, de 06 de fevereiro de 2006.

. Lei 11.494, de 20 de junho de 2007, que regulamenta o Fundo de Manutenção e Desenvolvimento da Educação Básica e de Valorização dos Profissionais da Educação - FUNDEB, de que trata o art. 60 do Ato das Disposições Constitucionais Transitórias; altera a Lei no 10.195, de 14 de fevereiro de 2001; revoga dispositivos das Leis nos 9.424, de 24 de dezembro de 1996, 10.880, de 9 de junho de 2004, e 10.845, de 5 de março de 2004; e dá outras providências.

GRAMSCI, A. Cadernos do Cárcere. vol. 1. 4 ed. Rio de Janeiro, 2004. 
MINISTÉRIO PÚBLICO DO ESTADO DO PARANÁ. Formosa do Oeste. Ofício Circular n⿳0 001/2007, de 27 de março de 2007.

. $4^{\mathrm{a}}$ Promotoria de Justiça da Comarca de Toledo - Promotoria de Defesa da Criança e do Adolescente e $2^{\text {a }}$ Promotoria de Justiça da Comarca de Toledo - Promotoria de Defesa do Patrimônio Público. Termo de Compromisso de Ajustamento de conduta $n^{0}$ 001/07. Toledo, em 26 de março de 2007.

PARANÁ. Conselho Estadual de Educação. Deliberação 03/06, aprovada em 09 de junho de 2006a. Normas para a implantação do Ensino Fundamental de 9 (nove) anos de duração no Sistema Estadual de Ensino do Estado do Paraná.

. $1^{\mathrm{a}}$ Vara da Fazenda Pública, Falência e Concordatas de Curitiba. Autos de Mandado de Segurança - Processo 2972/2006. Curitiba, 2006b.

. $1^{\mathrm{a}}$ Vara da Fazenda Pública, Falência e Concordatas de Curitiba. Concessão de Liminar. Ação Civil Pública n. 402/2007. Curitiba, 2007a.

- Tribunal de Justiça do Estado. Suspensão de Liminar n. 412996-0, da $1^{\text {a }}$ Vara da Fazenda Pública, Falência e Concordatas de Curitiba. Ação Civil Pública n. 402/2007. 02 de maio de 2007. Curitiba, $2007 \mathrm{~b}$. 